\title{
Para Ler Jon Elster: Limites e Possibilidades da Explicação por Mecanismos nas Ciências Sociais*
}

José Luiz de Amorim Ratton Júnior Jorge Ventura de Morais

\section{INTRODUÇÃO}

F ste artigo tem como escopo investigar os limites, as tensões e as laE cunas do enfoque teórico-metodológico ${ }^{1}$ proposto por Jon Elster, caracterizado por um tipo de explicação intencional-causal, que tem por pressuposto o individualismo metodológico ${ }^{2}$ e que elege a busca por mecanismos explicativos como estratégia analítica fundamental.

Inicialmente, será feita uma breve exposição histórica da trajetória teórica do autor norueguês, bem como da sua "metodologia da explicação". Em seguida, esta será submetida à análise mediante o levantamento e a discussão de algumas objeções a tal abordagem.

\section{A TRAJETÓRIA DE JON ELSTER ${ }^{3}$}

Um dos traços mais marcantes da filosofia das ciências sociais de Jon Elster (1985) é a sua defesa permanente e fiel do individualismo meto-

\footnotetext{
* Uma versão preliminar deste trabalho foi apresentada no XXIII Encontro Anual da Associação Nacional de Pós-Graduação e Pesquisa em Ciências Sociais - ANPOCs em 1999. Agradecemos aos pareceristas anônimos de Dados as sugestões que foram incorporadas ao texto final deste artigo, bem como a Tema Pechman pela revisão cuidadosa.

DADOS - Revista de Ciências Sociais, Rio de Janeiro, Vol. 46, nº2, 2003, pp. 385 a 410.
} 
dológico. Para ele, trata-se de uma doutrina em que todos os fenômenos sociais - sua estrutura e sua mudança - são, em princípio, explicáveis de forma que somente envolvam indivíduos - suas propriedades, seus objetivos, suas crenças e suas ações.

A variante de Elster do individualismo metodológico esteve, inicialmente, associada à ênfase dada pelo autor à utilidade das ferramentas da teoria da escolha racional para a explicação social. Essa versão forçaria o cientista social a voltar-se para aqueles processos no plano individual que produzem resultados sociais. A teoria da escolha racional ofereceria um relato geral a respeito do que são esses processos no plano individual - otimização, ordenamento de preferências etc. Parafraseando Little (1991), funciona como um programa de pesquisas para as ciências sociais: explica resultados sociais como o produto agregado do cálculo dos indivíduos em busca de seus interesses, dado suas crenças e seu ambiente de escolha. Esse programa seria plausível porque seres humanos são seres propositivos, portanto, dotados de intencionalidade, capazes de formar crenças e escolher ações tendo por base seus objetivos e crenças.

Como mencionado anteriormente, isso não significa dizer que os indivíduos sejam sempre racionais ou que apresentem racionalidade plena $^{4}$. Note-se que boa parte do trabalho de Elster se debruça sobre as falhas da racionalidade e sobre a irracionalidade ${ }^{5}$. Por outro lado, isso implica que a teoria da escolha racional fornece um ponto de partida comum para a análise dos fenômenos sociais.

No decorrer de sua trajetória intelectual, Elster passa a dar atenção especial ao papel de normas e valores na motivação e na restrição da escolha individual. Reconhecendo que a referência a sistemas normativos tem seu lugar na teoria individualista da ação social, o autor elabora uma teoria da motivação individual empiricamente mais adequada e modelos de processos sociais mais complexos.

Note-se que tal "alargamento teórico" é feito em consonância com o individualismo metodológico - normas sociais podem ser introduzidas na explicação individualista, pois elas apenas "materializam" sua existência quando incorporadas às ações, sanções, gestos de aprovação e desaprovação de indivíduos particulares (Elster, 1989a). Mais recentemente, Elster tem incorporado ao seu trabalho teórico os conceitos de cultura e de emoções. Com o primeiro (idem, 1999b), ele dá 
continuidade à inclusão das normas sociais como elementos motivadores da ação. Com o segundo, ele alarga ainda mais o conteúdo "expressivo" do seu individualismo metodológico, juntando a ele, de forma não residual, elementos que antes entravam em seu modelo teórico apenas sob o guarda-chuva conceitual da irracionalidade ou das falhas da racionalidade.

Para Elster, emoções são um tópico negligenciado nas ciências sociais contemporâneas, especialmente nas versões tributárias dos pressupostos antropológicos encontrados na teoria econômica neoclássica ${ }^{6}$. Ele propõe então uma agenda teórica para a investigação das emoções na vida social: o papel destas na sustentação das normas sociais, o papel das normas sociais na regulação das emoções, as interconexões entre racionalidade e emoções (emoções podem ser consideradas mais ou menos racionais, a interferência suposta das emoções sobre a racionalidade ou o contrário e a possibilidade de planejamento na vida emocional) etc.

Como o próprio Elster (1991) sugere, sua trajetória intelectual apresenta mais continuidade do que desenvolvimento. Compartilhamos a idéia de que sua concepção atual a respeito das ciências sociais permanece fiel àquela formulada no final dos anos 70 e início dos 80 , assim como seus conceitos centrais na explicação dos fenômenos sociais apresentam mais reformulações do que propriamente rupturas. Se pudermos sintetizar sua obra em poucas frases - excluindo propositadamente sua discussão sobre a natureza da explicação em ciências sociais, que será feita logo abaixo -, talvez deva ser dito que:

1) Uma das maneiras de ler um mapa das motivações humanas seria classificando-as da seguinte forma: às vezes, as pessoas perseguem seus objetivos agindo racionalmente; outras, impulsionadas por suas emoções; outras tantas, seguindo as normas sociais. A ação racional tem prioridade porque com maior freqüência procuramos agir racionalmente.

2) É necessário incorporar às ciências sociais, cada vez mais, a busca pela compreensão do comportamento não racional, partindo do suposto de que tais comportamentos não são residuais e devotando especial atenção às contradições mentais relativas a esse tópico.

3) Normas sociais, cultura, emoções e racionalidade podem e devem ser entendidas nos termos do individualismo metodológico. 


\section{A NATUREZA DA EXPLICAÇÃO EM JON ELSTER ${ }^{7}$}

A leitura atenta da obra de Elster permite-nos identificar a construção de uma posição teórica que afirma que a explicação em ciências sociais deve estar fundada sobre os seguintes princípios: a intencionalidade-causalidade; o individualismo metodológico articulado com um programa reducionista; um enfoque baseado em mecanismos, que busca estabelecer tais "unidades explicativas" (os mecanismos) como o artifício-chave para a elucidação do funcionamento (como e por quê) da vida em sociedade. Nas próximas seções, discutiremos tais princípios, que nos permitem explicitar a perspectiva central orientadora da investigação aqui realizada.

\section{A Explicação Intencional-Causal}

Segundo Elster, a explicação intencional-causal é típica das ciências sociais. Reconstruamos o seu argumento. Para ele, as duas principais tarefas da filosofia da ciência seriam explicar os traços que são comuns a todas as ciências e esclarecer o que coloca algumas delas à parte de outras (idem:1983a).

Dessa maneira, o autor busca estabelecer rupturas e continuidades entre a física, a biologia e as ciências sociais. Discutindo semelhanças e diferenças quanto ao método, Elster propõe que o método hipotético-dedutivo é aquele relacionado à verificação em todas as ciências empíricas $^{8}$, inclusive as ciências sociais. Mas que tipo de explicação pode ser adequado para cada domínio de pesquisa científica?

A resposta localizará a física anterior à teoria da relatividade e à mecânica quântica como o exemplo quase puro de explicação causal (não faria sentido falar em intenções no mundo físico); a biologia como o exemplo paradigmático de explicação funcional (comportando também explicação subfuncional e suprafuncional); as ciências sociais como o espaço reservado da explicação intencional, admitindo, entretanto, explicação subintencional e supra-intencional.

Mas é preciso observar que nas ciências sociais todos os fenômenos cobertos pela explicação intencional também podem ser explicados causalmente. Verificaríamos "causalidade subintencional" quando estivessem em jogo operações mentais que não são governadas por vontade ou intenção, mas que têm lugar por trás das intenções dos indivíduos. E, por outro lado, poderia ser percebida a "causalidade su- 
pra-intencional", quando há interação causal entre atores intencionais, ou seja, quando há resultados não esperados pelas ações intencionais.

A explicação intencional-causal é o tipo próprio das ciências sociais, pois compatibiliza o elemento causal, estruturador de qualquer ciência, com a especificidade do elemento intencional, incorporando normativamente no nível explicativo aquilo que é traço constitucional humano: a liberdade e a autonomia (idem, 1978) ${ }^{9}$.

\section{Explicação, Individualismo Metodológico e Redução}

Observemos agora como Elster articula a explicação intencional-causal com dois outros pressupostos metodológicos de seu empreendimento teórico: o individualismo metodológico e o reducionismo.

Como foi discutido anteriormente, Elster considera que fenômenos sociais são explicáveis apenas em termos dos indivíduos - suas características, seus fins, suas crenças. Dessa maneira, a ação intencional é a unidade elementar da vida social e é motivada pelos desejos e crenças dos indivíduos. Os fenômenos sociais resultariam da ação e da interação entre eles.

A explicação em ciências sociais deve ser, portanto, capaz de reduzir fenômenos complexos a seus elementos constitutivos: as ações individuais. Tal posicionamento epistemológico - o individualismo metodológico - deve ser entendido, segundo Elster (1986), como uma forma de reducionismo explicativo. O autor nos diz que para ir de instituições sociais e padrões agregados de comportamento para indivíduos utiliza-se o mesmo tipo de operação de quando se vai de células para moléculas. E explicar é fornecer um mecanismo, abrir uma caixa-preta e mostrar as peças e engrenagens, os desejos e crenças dos indivíduos que geram o resultado "social" agregado.

A estratégia explanatória reducionista obedeceria a dois estágios: primeiro, é necessário explicar por que macroestados no tempo $t$ influenciam o comportamento dos indivíduos motivados por certos objetivos. Em seguida, como essas ações individuais contribuem para novos macroestados no tempo $t+1$. 
Problemas e quebra-cabeças podem ser colocados em qualquer nível, mas a solução deve ser buscada, prioritariamente em um nível de agregação menos elevado. A própria definição de prática científica estaria comprometida em sua origem com a busca de uma explicação em um nível mais baixo que o do explanandum, sendo a busca por microfundamentos um traço onipresente e pervasivo da ciência.

Por outro lado, observa-se em Elster uma receptividade ao argumento das propriedades emergentes, ou seja, à idéia de que os "arranjos sociais resultantes" das interações entre os indivíduos são ao mesmo tempo produto das interações entre eles, assim como qualitativamente diferentes das unidades mínimas das quais emergiram.

Enfatize-se que o individualismo metodológico, enquanto dimensão central do programa reducionista de Elster, está inteiramente articulado com a afirmação de que as ciências sociais devem oferecer explicações intencionais-causais: a explicação intencional das ações individuais juntamente com a explicação causal da interação entre os indivíduos.

\section{Explicação e Mecanismos}

Nos tópicos anteriores, vimos como Elster articula a explicação intencional-causal, típica das ciências sociais (segundo este autor), com o individualismo metodológico e o reducionismo. Estes três pontos de partida metodológicos constituem os fundamentos da síntese metodológica de Elster e possibilitarão o entendimento do que nomeamos como síntese metodológica elsteriana: a explicação por mecanismos.

Dessa maneira, como acreditamos que pode ser identificada nos últimos escritos do autor a síntese do seu projeto explicativo, postulamos que a idéia de "mecanismos" não só não é incompatível com os elementos anteriores (intencionalidade-causalidade, individualismo metodológico, reducionismo), como dá a eles um sentido mais completo. Para compreender o papel dos mecanismos na construção da explicação, será necessário, introdutoriamente, localizar Elster no interior de um "movimento" mais amplo das ciências sociais contemporâneas, que coloca a explicação através de mecanismos como estratégia explanatória fundamental. 


\section{O que são mecanismos sociais?}

Um enfoque teórico-metodológico baseado em mecanismos, como o proposto por Elster, pode ser articulado a um conjunto de autores que assumem tal perspectiva. Nas linhas que se seguem, tentaremos resumir o "estado-da-arte" do debate sobre mecanismos nas ciências sociais.

A literatura recente sobre mecanismos sociais (Stinchcombe, 1998; Hedström e Swedberg, 1998; Elster, 1999a) propõe distintas, mas de certa forma aproximadas, concepções do que é um mecanismo social. Se partirmos de Merton (1968), mecanismos são processos sociais que têm conseqüências para as partes designadas da estrutura social. A principal tarefa da sociologia deve ser identificar mecanismos e estabelecer as condições sob as quais eles ocorrem, falham etc. Por outro lado, os mecanismos são os "tijolos", componentes básicos do edifício das teorias de médio alcance.

Um outro funcionalista heterodoxo, Stinchcombe (1998:267), afirma que mecanismos são partes de teorias acerca de entidades em um nível diferente (por exemplo, indivíduos) do de outras entidades sobre as quais se teoriza (por exemplo, grupos). Tais partes fariam com que a teoria do nível mais elevado ganhasse flexibilidade e acurácia.

No âmbito da tradição explicitamente individualista metodológica, destaca-se a definição de Thomas Schelling (1998), que acredita que um mecanismo pode ser considerado um conjunto de afirmações que fornecem um relato plausível de como inputs e outputs estão ligados uns aos outros.

Traços centrais das definições apontadas acima são: a ênfase teórico-analítica, o nível de generalidade intermediário (da explicação) e a vinculação com a necessidade de uma explicação em termos de causalidade como elemento constituidor das ciências sociais.

A explicação fundada em mecanismos é proposta como alternativa metodológica a quatro outras posições, e sua especificidade consiste exatamente na recusa da lógica subjacente a tais posições, a saber:

1) Pode-se dizer que o enfoque por mecanismos é uma tentativa de superar o modelo dedutivista de inspiração popperiana/hempeliana segundo o qual a explicação se dá por meio de subsunção dedutiva, 
sob leis universais (interpretadas como regularidades empíricas). Parte-se do princípio de que tal subsunção simplesmente generaliza problemas. O que se exige para uma explicação genuína é a introdução de novos conceitos que não estejam contidos no explanandum, ou, em outros termos, modelos descrevendo mecanismos sociais geradores plausíveis. Além disso, dois outros pontos revelam a fraqueza dessa posição: a ausência de explicações em ciências sociais, em conformidade com esse modelo dedutivista canônico; a exigência de simetria entre explicação e previsão, dado que a ciência social apresenta uma baixa capacidade preditiva.

2) A explicação por mecanismos difere não somente da mera subsunção, mas também do relato compreensivo ou interpretativo, próximo da etnografia. A invocação da Verstehen não faria referência necessária a qualquer mecanismo social. Ela simplesmente sugeriria uma fonte interna (mental) da ação individual (social ou não) sem que qualquer mecanismo explicativo estivesse sendo especulado ou descoberto: tais relatos compreensivos podem ser (e ocasionalmente são) meras descrições em linguagem ordinária ou em termos de psicologia popular (Bunge, 1997).

3) Um terceiro adversário da explicação por mecanismos seria o que se convencionou chamar de grandes sínteses na teoria social contemporânea, ao modo de Jeffrey Alexander, Anthony Giddens, Jürgen Habermas e Pierre Bourdieu. Tais sínteses procuram incorporar, em modelos explicativos de grande abrangência, como a nomologia e idiografia, macrossociologia e microssociologia, enfoques "estruturalistas" e "voluntarísticos". As principais deficiências desse tipo de construção de teoria são: a) incapacidade de fornecer efetivamente explicação sobre como ações sociais são agregadas se convertendo em estruturas, e como a estrutura é convertida em ação social pelos indivíduos; b) ênfase discursiva sobre temas epistemológicos, ontológicos e de filosofia da ciência desproporcional à teorização efetiva sobre o mundo social (Van den Berg, 1998:205).

4) Finalmente, o enfoque por mecanismos busca superar as limitações de um enfoque centrado nas relações entre variáveis. Um modelo de análise causal estatisticamente ancorado não explica nada por si mesmo, simplesmente sumariza o fenômeno (Boudon, 1998). Modelos teóricos, que incluem necessariamente os mecanismos geradores responsáveis pela relação observada entre as variáveis, são necessários 
para tornar inteligíveis os resultados de uma análise empírica. Isto não quer dizer que a pesquisa quantitativa não seja essencial às ciências sociais, tanto para propósitos descritivos quanto para testar teorias. No entanto, o ponto crítico que se quer enfatizar é a exigência de algum tipo de integração entre teoria e evidência. Se considerarmos que um mecanismo social é um relato de como a mudança em alguma variável é produzida - uma conceitualização do que ocorre no processo -, explicações sociológicas podem ser "reintroduzidas" na sociologia, dirigindo o foco para mecanismos específicos mediante os quais a mudança é produzida nos processos sociais. Isto pode resultar na especificação de tais relações em um modelo matemático, desde que estabelecido o foco sobre a mudança e a sua forma (teoricamente explicada) de ocorrência (Sorensen, 1998).

\section{Premissas da explicação por mecanismos}

Estabelecidos os antípodas da explicação por mecanismos, podemos passar agora à discussão do que seriam os postulados fundamentais do "enfoque mecanísmico" (Bunge, 1997), o qual, segundo Hedström e Swedberg (1998), pode ser caracterizado, grosso modo, por quatro traços fundamentais:

1) Explicações sociológicas ou em ciências sociais devem ser baseadas em ações, isto é, os atores e não as variáveis são os agentes. Portanto, não podem ser construídas sobre meras associações entre variáveis, mas devem fazer referência direta às causas e conseqüências da ação individual voltada para o comportamento de outros ${ }^{10}$.

A explicação fundada em mecanismos, usualmente, invoca um agente causal que são atores individuais, e a ciência social deve sempre fazer referência às causas e conseqüências das ações desses indivíduos. Tal princípio, o individualismo metodológico, estaria intimamente ligado à idéia central da explicação baseada em mecanismos: a compreensão do fenômeno é aumentada com o ato de tornar explícito o mecanismo gerador subjacente que liga um estado ou evento a outro; e nas ciências sociais as ações (individuais) constituem essa ligação. Dessa maneira, o conjunto de autores comprometidos tanto com a explicação por mecanismos, quanto com o individualismo metodológico, defende que fenômenos sociais são explicáveis apenas em termos dos indivíduos, suas características, seus fins, suas crenças (idem). A ação individual é a unidade elementar da vida social. Os fenômenos so- 
ciais resultam da ação e da interação entre indivíduos. A explicação nas ciências sociais deve ser, portanto, capaz de reduzir fenômenos complexos a seus elementos constitutivos, ou seja, às ações individuais.

2) Explicações sociológicas ou em ciências sociais devem buscar precisão elucidativa. Em outras palavras, não devem estar situadas em um nível de teorização tal que implique "indeterminação explicativa", nem devem tentar estabelecer leis sociais gerais, improváveis de existirem no domínio da sociologia.

Embora alguns autores, como Elster ou mesmo Merton, não descartem uma eventual tentativa - limitada e futura - de passagem dos mecanismos à teoria geral, exige-se, no mínimo, que possamos identificar com antecedência as condições nas quais um ou outro mecanismo é posto em ação.

3) Explicações sociológicas ou em ciências sociais necessitam, contudo, de um grau de abstração que permita a seleção dos fatores relevantes para a construção de modelos. Constitui-se, assim, o que chamaremos de enfoque analítico. A característica-chave desse enfoque é construir um modelo analítico da situação a ser examinada, formulado inicialmente de maneira a incluir somente elementos que se acredita serem essenciais.

O ponto mais importante a ser ressaltado é que o alvo da análise teórica é esse modelo, e não a realidade que ele pretende explicar (idem). No entanto, na medida em que o modelo incorpora os elementos essenciais da situação concreta, os resultados da análise teórica certamente ajudarão a esclarecer algo sobre a situação no "mundo real" que o modelo pretende explicar.

Em outros termos, o que se quer acentuar aqui é que mesmo os relatos mais detalhados da realidade põem em prática seleções de traços, são sempre modelos de situações concretas e em qualquer ocasião distorcerão a realidade, acentuando alguns aspectos e ignorando outros. Nas palavras de Hernes (1998), parodiando Claude Monet, cientistas sociais não pintam pessoas, pintam imagens de pessoas.

4) Explicações sociológicas ou em ciências sociais devem operar através de redução, buscando tornar claro o que liga input a output, expla- 
nans a explanandum. Em outras palavras, é necessário abrir a caixa-preta colocada entre o que é causa e o que é efeito.

Os quatro pontos assinalados anteriormente podem ser considerados o núcleo de um enfoque baseado em mecanismos (apesar de diferenças mais ou menos significativas entre alguns autores) e a partir deles pode ser constituído o que Hedström e Swedberg chamam de "um estilo de ciência social que se debruça sobre quebra-cabeças ou paradoxos sociais de médio alcance para obter uma explicação a um só tempo precisa, abstrata e baseada em ações individuais" (1998:25).

\section{Tipologias de mecanismos sociais}

Mesmo resguardando o caráter abstrato do empreendimento analítico da explicação por mecanismos, uma compreensão mais complexa desse enfoque explicativo exige que detalhemos em um nível mais específico a existência desses "constructos analíticos".

Alguns autores podem fornecer algumas pistas. Segundo Bunge (1997), haveria na ciência mecanismos de muitos tipos: eletromagnéticos, nucleares, químicos, celulares, intercelulares, ecológicos, econômicos, políticos. Nas ciências sociais, especificamente, conflito e cooperação, participação e segregação, institucionalização e rebelião, imitação e mercado, migração e colonização, inovação tecnológica e controle social sob várias formas. No entanto, precisamos agrupá-los em tipos que facilitem a tarefa de fornecer explicações tanto no plano de ocorrência macrossociológico dos fenômenos sociais, quanto no da sua necessária fundamentação microssociológica. Dessa maneira, explicações apropriadas da mudança e/ou variação no plano macro devem mostrar como macroestados em um determinado ponto influenciam o comportamento de atores individuais, e como essas ações geram novos macroestados em um momento posterior.

Duas tipologias de mecanismos (baseadas em critérios diferentes de separação) podem nos ser úteis:

1) Segundo Coleman (apud Hedström e Swedberg, 1998), três tipos de mecanismos estariam em operação nas ciências sociais:

a) Mecanismos situacionais (macro/micro) - fazem a ligação entre a estrutura social ou outros estados e as crenças, desejos e oportunida- 
des de algum ator individual (os exemplos aqui seriam todos os mecanismos formadores de crenças e de preferências).

b) Mecanismos formadores de ação (micro/micro) - aqueles relacionados a todas as possibilidades de combinação específica de desejos individuais, crenças e oportunidades de ação, gerando uma ação específica. São mecanismos de natureza psicológica e sociopsicológica, tal como dissonância cognitiva.

c) Mecanismos transformacionais (micro/macro) - aqueles através dos quais as ações individuais são transformadas em algum tipo de resultado coletivo, pretendido ou não (os exemplos clássicos são os modelos derivados da teoria dos jogos).

2) Gambetta (1998) propõe uma classificação que é compatível com a anterior. Segundo ele, para evitar confundir níveis de análise, devemos distinguir mecanismos individuais propriamente ditos e os processos mediante os quais eles são desencadeados por condições sociais (macro/micro), gerando resultados sociais (micro/macro). Mecanismos são aquelas formulações mínimas sobre a "composição" dos agentes que se requer para deduzir como eles interagem com os outros e respondem às condições externas.

As duas classificações propostas acima devem ser compreendidas levando-se em conta três pressupostos fundamentais que auxiliam a elucidar a dinâmica de funcionamento da explicação por mecanismos:

a) A maior parte dos fenômenos sociais requer mais que um mecanismo para fazer sentido. Mecanismos interagem uns com os outros formando concatenações de mecanismos (idem).

b) Os efeitos produzidos pelos mecanismos no nível empírico dependem de condições contingenciais, incluindo aquelas produzidas por outros mecanismos (Sayer, 1998).

c) Mecanismos apresentam-se sob a forma de "famílias": podemos agrupá-los a partir de critérios que indiquem mecanismos que produzam resultados similares e desfrutem similaridades e/ou diferenças (Schelling, 1998).

As classificações acima, por mais diversas que sejam, não são antagônicas; pelo contrário, complementam-se, além de compartilharem 
implicitamente um pressuposto comum: indicam que, de uma forma ou de outra, a utilização de mecanismos sociais como estratégia analítica coloca a necessidade de algum tipo de classificação que permita uma separação, para efeito de utilidade explicativa efetiva, dos níveis de teorização (micro/macro) dos principais tipos de mecanismos e das possibilidades de interação entre eles.

\section{Elster e os mecanismos}

Compreendido o contexto mais amplo dos enfoques teóricos baseados em mecanismos, podemos agora entender como Elster articula seus pressupostos metodológicos discutidos anteriormente (intencionalidade-causalidade, individualismo metodológico e projeto reducionista) com a "perspectiva mecanísmica".

Inicialmente, cinco distinções fundamentais fazem-se necessárias, segundo o autor (Elster, 1989a; 1999a):

a) Explicações causais devem ser distinguidas de proposições causais verdadeiras. Citar a causa não é suficiente, o mecanismo causal deve ser indicado e elucidado. Não basta, portanto, afirmar que pobreza gera crime, ou que educação aumenta renda, é preciso mostrar como, e através de que mecanismos, a situação de pobreza produz criminalidade ou a elevação do nível educacional produz mais renda.

b) Relacionada com a distinção anterior, está a idéia de que explicações causais devem ser discernidas de afirmações sobre correlação. Mas, aqui, o foco de Elster é outro: se um evento de um certo tipo é invariável ou usualmente seguido por um de outra espécie, isto não nos permite dizer que eventos do primeiro tipo acarretam eventos do segundo, porque há outra possibilidade: os dois poderiam ser efeitos comuns de um terceiro.

c) Explicações causais devem ser distinguidas de afirmações sobre necessitação. Explicar um evento é fazer um relato de por que e como este aconteceu. Dizer que poderia ter ocorrido de outra maneira não explica efetivamente o evento-problema que se quer explicar. $O$ pano de fundo dessa distinção é a conhecida crítica de Elster à explicação funcional.

d) Explicações causais devem ser isoladas do ato de contar estórias. Uma explicação genuína daria conta do que aconteceu, como aconte- 
ceu. Contar uma estória é dar conta do que ocorreu e como poderia ter ocorrido. Aqui, Elster busca uma distinção do relato etnográfico, da mera descrição, da ausência de ambição explanatória nas ciências sociais.

e) Finalmente, explicações causais devem ser consideradas distintas de predições. Pode-se explicar sem predizer e predizer sem explicar. Tome-se como exemplo a coexistência de dois mecanismos opostos, sem que se tenha uma teoria que nos diga quando um ou outro irá operar, ou qual a direção e a intensidade de cada mecanismo na produção de um saldo líquido que abra caminho tanto para uma explicação mais avançada, quanto para a previsão.

Os cinco pontos acima nos mostram o que não é uma explicação por mecanismos. Podemos agora passar ao seu conteúdo propriamente dito.

Para Elster (idem; idem), explicar é fornecer um mecanismo, abrir a caixa-preta e mostrar as peças e engrenagens, porcas e parafusos da maquinaria interna da vida social. O termo mecanismo relaciona-se a cadeias intencionais de um objetivo para uma ação, como também cadeias causais de um evento para o seu efeito. O papel dos mecanismos é duplo: eles nos tornam capazes de ir do maior para o menor, das sociedades para os indivíduos; eles reduzem o intervalo de tempo entre explanans e explanandum. Um mecanismo fornece uma cadeia contínua e contígua de links intencionais e causais: ele abre uma caixa-preta, que é uma falha, algo obscuro, na cadeia explicativa ${ }^{11}$.

Para Elster, mecanismos são padrões causais facilmente reconhecíveis, que ocorrem freqüentemente e são desencadeados sob condições geralmente desconhecidas e com conseqüências indeterminadas. Elster afirma que mecanismo é algo intermediário entre leis e descrições. Um mecanismo fornece uma explicação porque ele é mais geral que o fenômeno que ele subsume. É próprio de um mecanismo não comportar uma aplicação universal que permita a predição e o controle dos eventos sociais, mas encarnar um encadeamento causal que seja suficientemente geral e preciso para que possa ser encontrado em contextos variados. Menos que uma teoria, é muito mais que uma descrição, pois pode servir de modelo a outros casos ainda não encontrados. 
A passagem dos mecanismos à teoria geral (não descartada por Elster, apesar de relativizada) exige que identifiquemos com antecedência as condições nas quais um ou outro mecanismo será posto em ação.

Contudo, o número de condições que encontramos na realidade é grande demais para que possamos estabelecer, para cada uma delas, o mecanismo característico. Assim, a explicação sociológica baseada em mecanismos pode ser considerada a um só tempo indispensável e insuficiente: indispensável, pois pode identificar os mecanismos que, de outro modo, não seriam percebidos; e insuficiente, pois seu poder de previsão é quase nulo (Elster, 1999a).

Um outro ponto relevante: deve-se considerar que o antônimo de mecanismo é uma lei científica. Uma lei afirma que, sob certas condições iniciais, um evento de um certo tipo (a causa) irá sempre produzir um evento de um outro tipo (o efeito). Reconhecendo que explicações por leis são melhores mas raras em ciências sociais, o autor afirma que a explicação por mecanismos opera quando e porque nós podemos identificar um padrão causal que se pode reconhecer entre situações e que fornece uma resposta inteligível para a pergunta: Por que os indivíduos fizeram aquilo?

Ressalte-se, pois, que a defesa de mecanismos não é um argumento contrário a explicações baseadas em leis, mas contrário ao argumento de que quando explicações falham - e elas freqüentemente o fazem -, nós devemos cair na narrativa ou descrição.

Apesar da adoção de um conceito de mecanismo que tem por antônimo a lei científica, Elster mantém como adversário explícito qualquer tipo de explicação que não possibilite a abertura da caixa-preta. A explicação por mecanismos permitiria que se ultrapassasse a constatação de uma regularidade observável de tipo caixa-preta (da qual não se sabe por que e como ocorre). Assim, contra leis e explicações do tipo caixa-preta, abandona-se a formulação $S e A$, então, sempre $B$, para adotarmos Se $A$, então, sempre $C, D$ e $B$ ou Se $A$, então algumas vezes $B$. Dessa perspectiva, mecanismos são bons porque eles nos tornam capazes de explicar quando as generalizações falham, bem como porque nos tornam capazes de fornecer melhores explicações. Compreendendo os detalhes da estória causal, reduz-se o risco de explanação espúria ${ }^{12}$. 
Pode ser dito então que o objetivo factível, alcançável, das ciências sociais - de um ponto de vista explanatório - não está em buscar melhores teorias, mas em identificar cada vez mais mecanismos ${ }^{13}$.

\section{A EXPLICAÇÃO EM ELSTER COMO PROBLEMA}

Feita a exposição do conteúdo da ciência social elsteriana, bem como da sua "metodologia da explicação", passemos agora à problematização desta última, a qual incide sobre os traços centrais apontados acima: a dimensão intencional-causal; o individualismo metodológico e o programa reducionista (que serão tratados conjuntamente); e a ênfase nos mecanismos.

Vejamos, então, um conjunto de objeções às disposições teóricas elsterianas. Em alguns casos, indicamos estratégias de superação de tais obstáculos a partir do próprio aparato teórico-metodológico do autor; em outros, identificamos como os impasses e as limitações teórico-metodológicos que localizamos são impedimentos à realização do projeto explicativo do autor nos termos por ele colocados.

\section{A Dimensão Intencional-Causal como Problema}

Para abordar o tema da explicação intencional-causal em Elster, inicialmente faremos uso das proposições de Bhargava (1992). Para este autor, na visão elsteriana, o intencionalismo é a estratégia que busca argumentos não baseados em leis, mas em afirmações explicativas justificadas por inferências práticas (o que constituiria uma síntese justificadora do enfoque por mecanismos). Suas variáveis explanatórias cruciais são estados intencionais dos indivíduos, desejos e crenças.

A principal força da explicação intencionalista residiria na sua habilidade em dar conta de várias entidades sociais que as visões holistas não dão. Contudo, o intencionalismo tem também suas limitações. Uma delas, sua falha em não reconhecer fatores causais. Mas como vimos anteriormente, esse não é um problema da abordagem elsteriana que apresenta como traço central do seu projeto explicativo a dimensão intencional-causal. No entanto, há uma outra limitação, e esta é de extrema importância. Para Elster, intenções são estados mentais realizados conscientemente (ou na consciência). Mesmo a estrutura da linguagem deve ser individualmente construída. $\mathrm{O}$ argumento seria o 
de que um mundo significativo (para o indivíduo) se tornaria impossível sem uma consciência individual.

Mas Bhargava também mostra que o argumento de Elster subentende um intelectualismo residual cheio de problemas. O intelectualismo pressupõe (sem explicitar) que o principal "objetivo" dos conceitos ou palavras é conhecer o mundo teoricamente, e o principal "objetivo" das sentenças é relatar fatos. Assim, relacionar verdades teóricas é definir a capacidade da mente.

No entanto, tal visão intelectualista mantém uma rígida distinção entre sujeito e objeto. O conhecimento só é possível através das representações individuais, o que se aplica tanto a outras mentes quanto à própria. Haveria uma conexão entre a posição de Elster e um resíduo cartesiano separando dicotomicamente corpo e alma, o que traria inconvenientes insustentáveis para a posição de nosso autor, pois a ação com um propósito é construída como se um comportamento associado a uma concepção anterior de alguma coisa fosse representado em uma tela interna da consciência. A concepção de mente, nessa visão, é no mínimo suspeita, pois um grande número de operações mentais, mesmo racionais, não pressupõe associação com qualquer estado mental interno. Muito do nosso conhecimento está embebido em habilidades e capacidades que não podem ou não necessitam ser teoricamente estabelecidas, colocadas de forma proposicional ou mesmo representadas. Dito de outra forma, Bhargava desafia a visão individualista do significado, admitida de certa forma por Elster, mostrando que os significados não são mera matéria de estados psicológicos, mas do fato de se possuir habilidades como requisito. Em outras palavras, significados são socialmente distribuídos e têm uma relação constitutiva com as práticas sociais, ou seja, apresentam um ineliminável caráter social.

Faltaria a Elster, então, como parte integrante de sua teoria da ação, uma concepção mais robusta da linguagem, para que sua concepção de explicação intencional pudesse ser desenvolvida a partir de uma teoria do significado que levasse em conta tal "ineliminável caráter social" dos significados e que, portanto, redefinisse a forma de operação dos mecanismos mentais ou intrapessoais, tanto motivacionais quanto cognitivos. 


\section{O Individualismo Metodológico e o Reducionismo como Problemas}

O individualismo metodológico pode ser classificado a partir da aceitação (ou não) de duas exigências: uma sobre entidades sociais e outra sobre as explicações sociais. Na primeira, há a negação da existência de entidades sociais independentes dos indivíduos; na segunda, a ênfase recai sobre a idéia de que relações explanatórias entre fatos sociais necessitam ser reduzidas a explicações entre fatos no plano dos indivíduos.

Como vimos, na discussão da estratégia de explicação por mecanismos em Elster, para tornar inteligível um fenômeno no âmbito individual, não é suficiente encontrar regularidades sociais ou funcionais entre entidades sociais. É necessário, contudo, fornecer um detalhado relato dos mecanismos no âmbito individual pelos quais as propriedades causais ou as necessidades funcionais do sistema social são impostas sobre outras instituições e práticas (é essencial produzir um relato dos microfundamentos de um dado processo social). Assim, macroexplicações são insuficientes, a menos que acompanhadas por uma análise em um nível de atividade individual que revele os mecanismos que fazem surgir o padrão a ser explicado. Do que foi dito acima algumas questões podem ser extraídas:

a) Uma postura teórica (como o individualismo metodológico), que não elimina necessariamente a existência do macroscópico em si, mas de fato nega-lhe qualquer poder causal inerente ao seu próprio nível, coloca em questão o próprio nível de existência ontológica do social (Lloyd, 1995). O argumento de Lloyd, que pode comprometer a força da posição individualista em Elster, é que, até na física, onde as explicações reducionistas são comuns, estas estão longe de ser universalmente aplicáveis. Muitos sistemas físicos macroscópicos só podem ser explicados como sistemas, e o comportamento de seus componentes, como partes de sistemas. A barreira fundamental ao sucesso das tentativas de explicação reducionista (e que comprometeria a estratégia elsteriana) é a irredutibilidade de determinados sistemas macroscópicos dotados de propriedades e poderes emergentes.

b) Segundo Bhargava (1992), apesar da defesa que Elster faz do reducionismo, ele praticamente oferece uma explicação dos fenômenos sociais efetivos em termos dos indivíduos típicos e de suas razões e 
causas típicas. Os mecanismos em questão envolvem as crenças e os desejos mais gerais que causam o comportamento individual de um certo tipo e em termos do qual um fenômeno social particular qualquer pode ser explicado.

Se isso acontece, como sugere Bhargava (idem), nós não temos realmente uma explicação reducionista. A identidade requerida entre objetos da explicação não é realizada. Isso pode ser uma forma válida de explanação e uma das formas pelas quais se separa correlações efetivas de correlações espúrias. É provável que, para toda explicação de macroestados, nós necessitemos de alguma estória típica em termos dos indivíduos, o que daria maior confiabilidade à nossa explicação. Mas microfundamentos não devem ser confundidos com microrredução ${ }^{14}$.

Portanto, talvez tenhamos que - a título de classificação e para entendê-lo adequadamente - "enfraquecer" o individualismo metodológico elsteriano e remetê-lo a um tipo de classificação no espectro das ciências sociais, mais distante do forte pólo individualista metodológico que Elster imagina estar (e que, portanto, deve reconhecer a possibilidade de um enfoque baseado em mecanismos cujos poderes causais estejam "situados" em um nível supra-individual).

\section{A Dimensão Mecanísmica da Explicação como Problema}

Vimos que Elster é claro quanto à superioridade metodológica da explicação por mecanismos nas ciências sociais. No entanto, à "natureza mecanísmica" da explicação uma objeção pode ser apontada: a evidência de associação entre duas variáveis nos dá, inicialmente, uma razão para acreditar que há uma relação causal de algum tipo afetando as variáveis sob escrutínio; mas como o próprio Elster alerta, isto não estabelece a natureza daquela relação. É necessário avançar uma hipótese sobre o mecanismo causal que produz as probabilidades observadas.

É evidente que em Elster a descoberta de regularidades, distribuições de probabilidades anormais e correlações pode ser evidência de relações causais, mas não é suficiente para a sua ocorrência. Sabe-se, no entanto, que fatos sobre regularidades indutivas podem ser úteis para identificar possíveis regularidades causais, mas o fundamental é a investigação sobre processos causais antes que possamos concluir 
que uma relação causal exista (nas palavras do autor: que mecanismo está operando?).

No entanto, em Elster, como apontado em Stinchcombe (1985), parece não haver nenhum tipo de critério relacionado à relevância indutiva de relações entre entidades que funcione ao menos como uma fonte de hipóteses causais e um método para avaliá-las empiricamente (e não como uma definição de causação). Em que medida isso não distanciaria o projeto teórico-metodológico do autor de sua dimensão explicativa de "fenômenos reais" e o aproximaria perigosamente de concepções superteorizantes - ao modo de Alexander, Bourdieu, Giddens e Habermas -, perdendo assim em capacidade explicativa efetiva dos fenômenos sociais (cf. Van den Berg, 1998).

\section{CONCLUSÃO}

Acreditamos que a "metodologia da explicação" elsteriana apresenta um caráter original, pois ao mesmo tempo que dialoga com os temas centrais das ciências sociais, assume, na contramão do mainstream, uma perspectiva individualista metodológica afirmativa, sem compromisso com os excessivamente amplos projetos de síntese que hoje vicejam.

A despeito disso, a natureza da explicação em Elster - resultante da associação entre uma perspectiva intencional-causal, o individualismo metodológico e uma ênfase analítica sobre os mecanismos - não está isenta de problemas e antinomias, como tentamos apontar neste texto.

A ausência de uma teoria do significado incorporada à sua teoria da ação, as aporias resultantes da adoção de uma tese individualista metodológica que ora se apresenta mais próxima de um pólo ontológico (forte) e ora se aproxima de um pólo epistemológico (fraco), e o silêncio acerca de critérios relacionados à relevância indutiva de relações entre entidades que possam ser úteis para a constituição de um repertório de hipóteses causais, bem como de um método para sua avaliação empírica, são desafios ao empreendimento elsteriano. Tais desafios não eliminam sua força, mas revelam os impasses teórico-metodológicos não só do individualismo metodológico, mas da própria teoria social contemporânea.

(Recebido para publicação em fevereiro de 2001)

(Versão definitiva em outubro de 2002) 


\section{Para Ler Jon Elster: Limites e Possibilidades da Explicação por Mecanismos...}

\section{NOTAS}

1. A metodologia deve ser entendida aqui como uma forma de crítica sistemática das noções, conceitos, inferências etc.

2. O individualismo metodológico não significa necessariamente: escolha racional, egoísmo, a natureza inata ou "dada" dos desejos e muito menos individualismo político (Elster, 1986; 1990), como muitas vezes é "mal-entendido" por alguns críticos.

3. Jon Elster publicou alguns livros em norueguês antes e um pouco depois da conclusão de seu doutorado em Paris, em 1971, sob orientação de Raymond Aron. Depois de seu doutoramento, suas principais obras foram Leibniz et Formation de l'Esprit Scientifique (1975); Logic and Society (1978); Ulysses and the Sirens (1979); Sour Grapes (1983); Explaining Technical Change (1983); Making Sense of Marx (1985); An Introduction to Karl Marx (1986); Solomonic Judgements (1989); Nuts and Bolts for the Social Sciences (1989); The Cement of Society (1989); Psychologie Politique (1990); Local Justice (1992); Strong Feelings: Emotions, Addiction, and Human Behavior (1999); Alchemies of the Mind: Rationality and the Emotions (1999); Ulysses Unbound: Studies in Rationality, Precommitment, and Constraints (2000). Ele também editou: The Multiple Self (1985); Foundations of Social Choice Theory (1986); Rational Choice (1986); Karl Marx: A Reader (1986); Constitutionalism and Democracies (1988); Alternatives to Capitalism (1989); Interpersonal Comparisons of Well-Being (1991); Choice Over Time (1992); The Ethical of Medical Choice (1994); Local Justice in America (1995); The Round Table Talks in Eastern Europe (1996); Deliberative Democracy (1998); Institutional Design in Post-Comunist Societies: Rebuilding the Ship at Sea (1998); Getting Hooked: Rationality and Addiction (1999).

4. As principais limitações da racionalidade, segundo Elster, são:

a) Sua indeterminação (mais de uma ação pode ser igualmente benéfica para o agente), que pode manifestar-se de duas maneiras: i) crenças, evidências ou ações racionais podem não existir. Quando os agentes não podem comparar todas as opções, seus ordenamentos de preferência são incompletos, e a teoria da escolha racional não pode funcionar como guia para a ação nem pode explicá-la; ii) agentes podem não ser capazes de estabelecer racionalmente o ótimo nível de evidências requeridas para uma ação racional, porque não têm acesso aos benefícios e custos marginais esperados da busca por informação.

b) Os indivíduos são irracionais quando podem ser racionais. Indivíduos reais fazendo escolhas não são completamente regulados por racionalidade. Fraqueza de vontade, emoções, impulsividade, auto-engano etc. interferem freqüentemente na tomada de decisões.

c) Na teoria das preferências subjacente à Teoria da Escolha Racional - TER, pressupõe-se que indivíduos tenham preferências consistentes, completas e ordenadas. Um exemplo importante é o da mudança de preferências endógenas (minhas ações hoje podem me fazer mudar de preferência amanhã). A utilização da otimização maximizadora, prescrita pela TER, não resolve o problema.

d) O problema do tempo: como o ator racional pode manter-se racional e ao mesmo tempo levar em conta utilidades futuras nas escolhas atuais que realiza. Em outros termos, como pode se proteger hoje de ações irracionais no futuro? (Elster, 1983b; 1984; 1989b). 
5. A investigação do "comportamento irracional", ou do comportamento que não é governado pela racionalidade, assume cada vez mais importância na obra de Elster, e passa a fazer parte do repertório de mecanismos de ação fundamentais proposto pelo autor. Desde a década de 80, o tema esteve presente em sua obra através de quatro principais problemas (Elster, 1983b; 1984): a) a ação racional sobre pressupostos irracionais a respeito do comportamento dos outros; $b$ ) a busca de realização de intenções irrealizáveis; c) as irracionalidades da ideologia, tratada como crença distorcida; d) as conseqüências não intencionais das distorções ideológicas.

6. Algumas razões podem ser apontadas como possíveis causas dessa omissão, segundo palavras do próprio Elster: “a impossibilidade de mensuração, a falta de boas teorias a respeito de como emoções são acionadas, o fato de as emoções derivarem mais propriamente de encontros com pessoas do que com bens materiais e não serem mediadas através do mercado e, finalmente, a dificuldade de maximização das emoções ao bel-prazer dos indivíduos" (Elster, 1999a; ver, também, 1999b).

7. Para o mapeamento inicial dos contornos da "filosofia das ciências sociais" no pensamento de Elster, seguir o seguinte percurso: em Logic and Society (1978), no apêndice II do capítulo 5, o autor apresenta-nos os contornos do seu enfoque intencional-causal, reapresentado brevemente no prefácio de Ulysses and the Sirens (1984) e desenvolvido de forma mais extensa nos três primeiros capítulos de Explaining Technical Change (1983a), nos quais o autor discute explicitamente o que considera próprio e impróprio nas ciências sociais, contrapondo-as à física e à biologia enquanto paradigmas alternativos de explicação. Os temas da causalidade e da intencionalidade são retomados no primeiro capítulo de Making Sense of Marx (1985), em um contexto de discussão crítica da obra de Marx. Os temas do individualismo metodológico e do programa reducionista são apresentados no artigo seminal Marxism, Functionalism and Game Theory (1982), no capítulo I de Making Sense of Marx (1985), no capítulo II de An Introduction to Karl Marx (1986), e nos capítulos II e VIII de Nuts and Bolts for the Social Sciences (1989a). A defesa mais desenvolvida de um tipo de explicação baseada em mecanismos está explicitamente colocada no capítulo I de Nuts and Bolts for the Social Sciences (1989a). Em Psychologie Politique (1990), especialmente em sua introdução, um novo tratamento é dado ao mesmo tema. E, finalmente, em “A Plea for Mechanisms" (1998), que reaparece modificado como o extenso capítulo I de Alchemies of the Mind (1999a), Elster apresenta-nos sua mais acabada versão sobre o tipo de explicação possível e desejável nas ciências sociais: a explicação por mecanismos.

8. Abordando de forma original o método compreensivo, Elster (1983a) afirma que se o método hermenêutico é entendido como um procedimento para verificação, ele torna-se uma subespécie do método hipotético-dedutivo aplicado aos fenômenos intencionais, com alguns traços particulares tendo em vista a natureza desses fenômenos. Portanto, se o método hermenêutico é visto como um método de formação de teoria, ele coincide com a formação de explicação intencional. Por outro lado, o que se convencionou chamar de método dialético pode ser visto como uma ferramenta para a formação de teorias, explorando a investigação das noções de contradições sociais e psicológicas, passíveis de tradução na linguagem-padrão "intencional mas causal" das ciências sociais. 
9. Elster $(1982 ; 1983 b ; 1985)$ afasta a possibilidade de explicação funcional nas ciências sociais, argumentando contra a idéia de que conseqüências podem explicar suas causas na ausência de um mecanismo demonstrado de feedback. O autor só admite a explicação funcional em biologia, por causa da existência de uma teoria geral - a Teoria da Evolução.

10. Observe-se que nem todos os autores que abraçam um enfoque explanatório baseado em mecanismos compartilham a filiação a um ponto de vista do individualismo metodológico. Exemplos notáveis são Bunge e Stinchcombe.

11. Embora o propósito de um mecanismo seja reduzir o intervalo de tempo entre causa e efeito, o sucesso da redução pode ser restrito, dependendo da capacidade de substituição das variáveis macro por variáveis micro (Hedström e Swedberg, 1998; Elster, 1999a).

12. Elster propõe uma classificação dos mecanismos. Mecanismos em geral ocorrem aos pares, por exemplo, "igual atrai igual" e "opostos se atraem" podem acompanhar um ao outro. Existiriam dois tipos gerais de mecanismos:

a) Mecanismos de tipo A: ocorrem quando a indeterminação diz respeito à cadeia (se há alguma) causal que será desencadeada em uma dada "situação social".

b) Mecanismos de tipo B: ocorrem quando podemos predizer que serão postas em ação duas cadeias causais que afetarão uma variável independente em direções opostas, deixando o efeito líquido indeterminado. Ainda para mecanismos de tipo $\mathrm{B}$, temos casos em que dois mecanismos opostos são desencadeados simultaneamente pela mesma causa, e casos em que um é desencadeado pelo outro. Elster classifica-os como B1 e B2, respectivamente.

Sintetizando, com mecanismos $\mathrm{A}$, nós não podemos saber qual deles será desencadeado; com mecanismos B, não somos capazes de saber o efeito líquido dos dois mecanismos opostos (Elster, 1999a).

13. Pode ser aqui aventado um parentesco entre a posição de Elster contra a Grande Teoria e a de Merton contra a Teoria Parsoniana. Não só porque Elster não acredita em uma "teoria geral dos campos" nas ciências sociais", como não crê na possibilidade de generalização e repetição - próprias das leis científicas - mesmo em teorias de médio alcance.

14. O argumento de Bhargava pode ser verificado em duas obras de Elster: em $A n$ Introduction to Karl Marx (1986), na seção sobre individualismo metodológico, Elster praticamente transforma a busca por microfundamentos em sinônimo de individualismo metodológico; e em Nuts and Bolts for the Social Sciences (1989a), no capítulo sobre Desejos e Oportunidades, apresenta o mesmo tipo de formulação. 


\section{REFERÊNCIAS BIBLIOGRÁFICAS}

BHARGAVA, R. (1992), Individualism in Social Science. Oxford, Clarendon Press.

BOUDON, Raymond. (1998), "Social Mechanisms without Black Boxes", in P. Hedström e R. Swedberg (orgs.), Social Mechanisms: An Analytical Approach to Social Theory. New York, Cambridge University Press.

BUNGE, Mario. (1997), “Mechanisms and Explanation”. Philosophy of the Social Sciences [on line]. dezembro <http:// proquest.umi.com>.

ELSTER, Jon. (1978), Logic and Society: Contradictions and Possible Words. New York, Wiley.

. (1982), "Marxism, Functionalism and Game Theory". Theory and Society, no 11, pp. 453-482.

. (1983a), Explaining Technical Change. Cambridge, Cambridge University Press.

(1983b), Sour Grapes - Studies in the Subversion of Rationality. Cambridge, Cambridge University Press.

. (1984), Ulysses and the Sirens (edição revista). Cambridge, Cambridge University Press.

. (1985), Making Sense of Marx. Cambridge, Cambridge University Press.

. (1986), An Introduction to Karl Marx. Cambridge, Cambridge University Press.

(1989a), Nuts and Bolts for the Social Sciences. Cambridge, Cambridge University Press.

(1989b), Solomonic Judgements - Studies in the Limitations of Rationality. Cambridge, Cambridge University Press.

. (1990), Psychologie Politique (Veyne, Zinoviev, Tocqueville). Paris, Les Éditions de Minuit.

. (1991), "Marxismo Analítico, o Pensamento Claro - Entrevista de Jon Elster a Esther Hamburger". Novos Estudos CEBRAP, $\mathrm{n}$ 을. 31 .

. (1998), "A Plea for Mechanisms", in P. Hedström e R. Swedberg (eds.), Social Mechanisms: An Analytical Approach to Social Theory. New York, Cambridge University Press.

(1999a), Alchemies of the Mind: Rationality and the Emotions. Cambridge, Cambridge University Press.

. (1999b), Strong Feelings. Emotions, Addiction, and Human Behavior. Cambridge, MIT University Press.

GAMBETTA, Diego. (1998), "Concatenations of Mechanisms", in P. Hedström e R. Swedberg (eds.), Social Mechanisms: An Analytical Approach to Social Theory. New York, Cambridge University Press.

HEDSTRÖM, P. e SWEDBERG, Richard. (1998), “Social Mechanisms: An Introductory Essay", in P. Hedström e R. Swedberg (eds.), Social Mechanisms: An Analytical Approach to Social Theory. New York, Cambridge University Press. 


\section{Para Ler Jon Elster: Limites e Possibilidades da Explicação por Mecanismos...}

HERNES, Gudmund. (1998), “Real Virtuality”, in P. Hedström e R. Swedberg (eds.), Social Mechanisms: An Analytical Approach to Social Theory. New York, Cambridge University Press.

LITTLE, Daniel. (1991), Varieties of Social Explanation. Oxford, Westview Press.

LLOYD, Christopher. (1995), As Estruturas da História. Rio de Janeiro, Jorge Zahar Editor.

MERTON, Robert. (1968), Social Theory and Social Structure. New York, The Free Press.

SAYER, Andrew. (1998), “Abstraction: A Realist Interpretation", in M. Archer et alii (orgs.), Critical Realism. London, Routledge.

SCHELLING, Thomas. (1998), "Social Mechanisms and Social Dynamics", in P. Hedström e R. Swedberg (eds.), Social Mechanisms: An Analytical Approach to Social Theory. New York, Cambridge University Press.

SORENSEN, Aage B. (1998), "Theoretical Mechanisms and the Empirical Study of Social Processes", in P. Hedström e R. Swedberg (eds.), Social Mechanisms: An Analytical Approach to Social Theory. New York, Cambridge University Press.

STINCHCOMBE, Arthur. (1985), "Can the Philosophy of Science Help Science?". Contemporary Sociology, vol. 14, no 2, pp. 164-166.

. (1998), “Monopolistic Competition as a Mechanism: Corporations, Universities, and Nation-states in Competitive Fields", in P. Hedström e R. Swedberg (eds.), Social Mechanisms: An Analytical Approach to Social Theory. New York, Cambridge University Press.

VAN DEN BERG, Axel. (1998), "Is Sociological Theory too Grand for Social Mechanisms?", in P. Hedström e R. Swedberg (eds.), Social Mechanisms: An Analytical Approach to Social Theory. New York, Cambridge University Press. 


\section{ABSTRACT \\ To Read Jon Elster: Limits and Possibilities of Explanation by Mechanisms in the Social Sciences}

The article aims to investigate and discuss not only the innovations but also the limitations, tensions, and gaps in Jon Elster's methodological concepts, characterized by a type of intentional-causal explanation whose premise is methodological individualism and which chooses the search for explanatory mechanisms as the fundamental analytical strategy. The Norwegian author's theoretical trajectory is reconstructed and articulated with his "methodology of explanation". Next, this "methodology of explanation" is submitted to analysis by raising and discussing some objections to this approach, as well as answers to such questions that can be found in Elster's work.

Key words: Jon Elster; explanation; mechanisms

\section{RÉSUMÉ}

Pour Lire Jon Elster: Limites et Possibilités de l'Explication par des Mécanismes dans les Sciences Sociales

Dans cet article, on cherche à discuter les innovations ainsi que les limites, tensions et lacunes des conceptions méthodologiques de Jon Elster, qui se caractérisent par un type d'explication intentionnelle causale, dont le pressuposé est l'individualisme méthodologique, qui choisit la recherche au moyen de mécanismes explicatifs comme sa stratégie analytique fondamentale. Le parcours théorique de l'auteur norvégien est reconstruit et articulé selon sa "méthodologie de l'explication". Ensuite, on analyse cette "méthodologie de l'explication" en répertoriant et discutant quelques objections qu'on lui fait, ainsi que les possibles réponses à ces questions qu'on peut rencontrer dans l'oeuvre d'Elster.

Mots-clé: Jon Elster; explication; mécanismes 